\title{
Artery of Adamkiewicz: a meta-analysis of anatomical characteristics
}

\section{Dominik Taterra ${ }^{1,2} \cdot$ Bendik Skinningsrud ${ }^{1,2}$ - Przemysław A. Pękala ${ }^{1,2} \cdot$ Wan Chin Hsieh ${ }^{1,3} \cdot$ Roberto Cirocchi $^{4}$. Jerzy A. Walocha ${ }^{1,2} \cdot$ R. Shane Tubbs ${ }^{5} \cdot$ Krzysztof A. Tomaszewski $^{1,6}{ }^{\mathbb{B}} \cdot$ Brandon Michael Henry $^{1}$}

Received: 1 February 2019 / Accepted: 1 April 2019 / Published online: 27 April 2019

(C) The Author(s) 2019

\begin{abstract}
Purpose The artery of Adamkiewicz (AKA) provides the major blood supply to the anterior thoracolumbar spinal cord and iatrogenic injury or inadequate reconstruction of this vessel during vascular and endovascular surgery can result in postoperative neurological deficit due to spinal cord ischemia. The aim of this study was to provide comprehensive data on the prevalence and anatomical characteristics of the AKA.

Methods An extensive search was conducted through the major electronic databases to identify eligible articles. Data extracted included study type, prevalence of the AKA, gender, number of AKA per patient, laterality, origin based on vertebral level, side of origin, morphometric data, and ethnicity subgroups.

Results A total of 60 studies ( $n=5437$ subjects) were included in the meta-analysis. Our main findings revealed that the AKA was present in $84.6 \%$ of the population, and patients most frequently had a single AKA (87.4\%) on the left side $(76.6 \%)$ originating between T8 and L1 (89\%).

Conclusion As an AKA is present in the majority of the population, caution should be taken during vascular and endovascular surgical procedures to avoid injury or ensure proper reconstruction. All surgeons operating in the thoracolumbar spinal cord should have a thorough understanding of the anatomical characteristics and surgical implications of an AKA.
\end{abstract}

Keywords Adamkiewicz artery · Anatomy · Great anterior radiculomedullary artery $\cdot$ Thoracoabdominal aneurysm $\cdot$ Aortic aneurysm

DT and BS contributed equally to this work.

Electronic supplementary material The online version of this article (https://doi.org/10.1007/s00234-019-02207-y) contains supplementary material, which is available to authorized users.

Krzysztof A. Tomaszewski krtomaszewski@gmail.com

1 International Evidence-Based Anatomy Working Group, Kraków, Poland

2 Department of Anatomy, Jagiellonian University Medical College, 12 Kopernika Street, 31-034 Kraków, Poland

3 First Faculty of Medicine, Charles University, Prague, Czech Republic

4 Department of Surgical Sciences, Radiology and Dentistry, University of Perugia, Perugia, Italy

5 Seattle Science Foundation, Seattle, WA, USA

6 Faculty of Medicine and Health Sciences, Andrzej Frycz Modrzewski KrakowUniversity, Kraków, Poland

\section{Introduction}

The artery of Adamkiewicz (AKA), also known as the great anterior radiculomedullary artery, is a major artery that joins the anterior spinal artery in the lower one-third of the spinal cord (Fig. 1) [1]. Because of its large role in feeding the spinal cord, many reports have stressed the importance of reattaching the intercostal or lumbar arteries to the AKA in the event of spinal cord ischemia following vascular and endovascular surgery (Fig. 2). Identification of the AKA preoperatively helps surgeons to determine the appropriate range of aortic lesions that require graft replacement [2]. Therefore, accurate localization and detailed anatomical knowledge of the AKA are important when planning surgical and interventional radiological treatments of thoracoabdominal diseases and spinal lesions in order to help reduce the risk of postoperative ischemic spinal complications and paraplegia.

The AKA is the most dominant anterior radiculomedullary artery and is responsible for the arterial blood supply to the spinal cord from T8 to the conus medullaris [3]. Its origin is highly variable and extends from the mid-thoracic level to the 


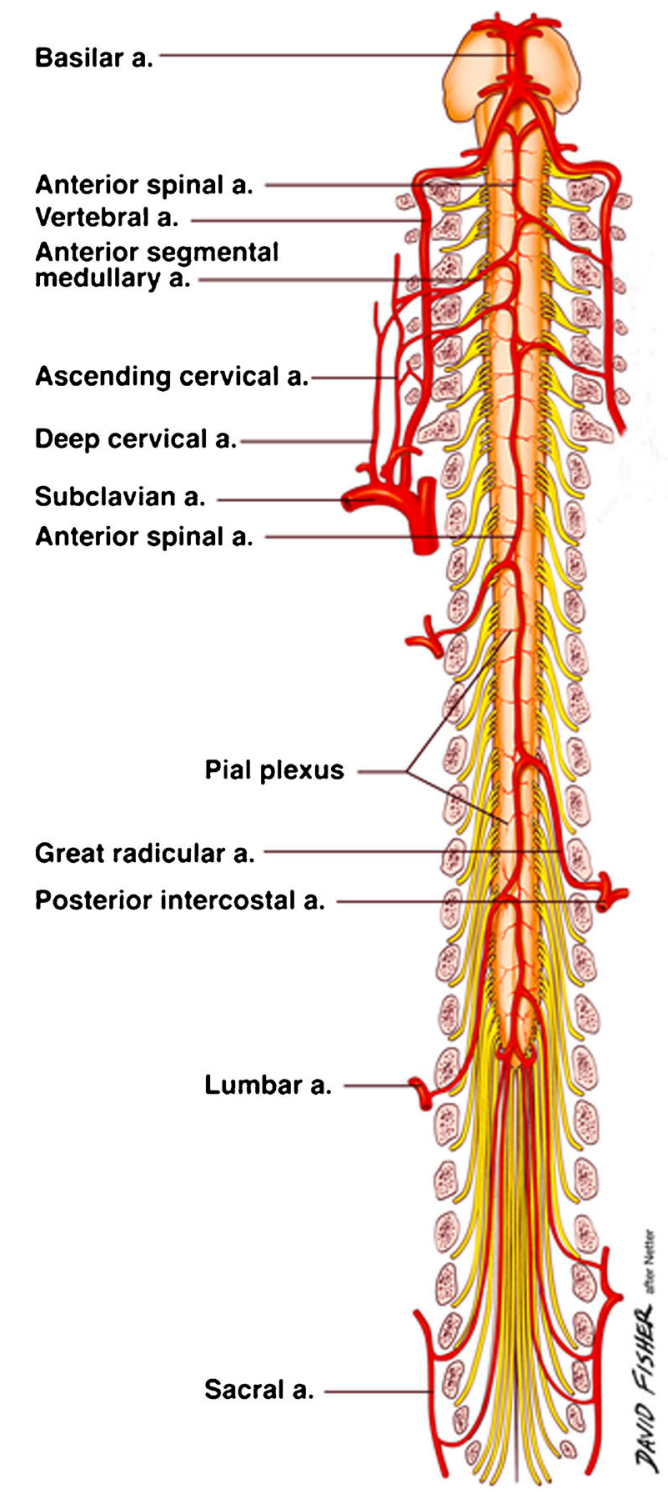

Fig. 1 Vasculature of the spinal cord - the artery of Adamkiewicz (great radicular a.)

lumbar levels, including the bilateral T3-T12 intercostal arteries [4] and L1-L4 lumbar arteries [5]. It typically arises from the T8-L1 neural foramina [6] from the left intercostal or lumbar arteries [7]. The AKA has a diameter of $0.8-1.3 \mathrm{~mm}$, and the distal portion of this artery, together with the anterior spinal artery, forms a characteristic "hairpin" turn [8] (Fig. 3). Various techniques have been devised to preoperatively identify the location and anatomy of this artery. Such techniques include computed tomography angiography (CTA), magnetic resonance angiography (MRA), and digital subtraction angiography (DSA), with the latter considered the gold standard [9].

The most important cause of injury to the AKA is iatrogenic, and in part, this is a factor of the high degree of variability in the anatomical location of this artery [10]. Preoperative AKA identification and its subsequent reconstruction or preservation may aid in reducing the incidence of postoperative neurological deficits and improving the outcomes of thoracolumbar surgical procedures. To this end, the aim of this study was to provide comprehensive data on the prevalence and anatomical characteristics of the AKA.

\section{Materials and methods}

\section{Search strategy}

A search of all major electronic databases (PubMed, EMBASE, ScienceDirect, China National Knowledge Infrastructure (CNKI), SciELO, BIOSIS, and Web of Science) was performed in order to identify potential articles. The following search terms were employed: artery of Adamkiewicz, arteria radicularis magna (ARM), radicularis magna, great radicular artery of Adamkiewicz, major anterior segmental medullary artery, great anterior segmental medullary artery, artery of the lumbar enlargement, arteria radicularis anterior magna, and great anterior radiculomedullary artery. A search through the references of the initially selected articles was conducted to identify any potential studies that were omitted. The authors adhered to the Preferred Reporting Items for Systematic Reviews and Meta-Analyses (PRISMA) guidelines throughout this metaanalysis (Supplement 1).

\section{Eligibility assessment}

An eligibility assessment was conducted by two independent reviewers. Studies were included in this meta-analysis if they (1) provided complete data on the prevalence of the AKA or (2) provided data on the anatomy of AKA. The following exclusion criteria were employed: case, case-series, conference abstracts, letters to editors, and studies not published in peer-reviewed journals. Studies that were originally published in languages other than English were translated by medical professionals who are fluent both in English and the original language of the manuscript. All differences of opinion among the reviewers concerning the eligibility of the studies were resolved by consensus through consultation with the author of the respective study.

\section{Data extraction}

Two reviewers carried out data extraction independently. The following data was extracted: publication year, country of origin, study type (cadaveric, CTA, MRA, DSA), prevalence data of AKA, number of AKAs per patient, laterality of the AKA, origin of the AKA based on the vertebral level, side of origin, and morphometric data. In cases of incomplete data, 
Fig. 2 Intraoperative image of the artery of Adamkiewicz

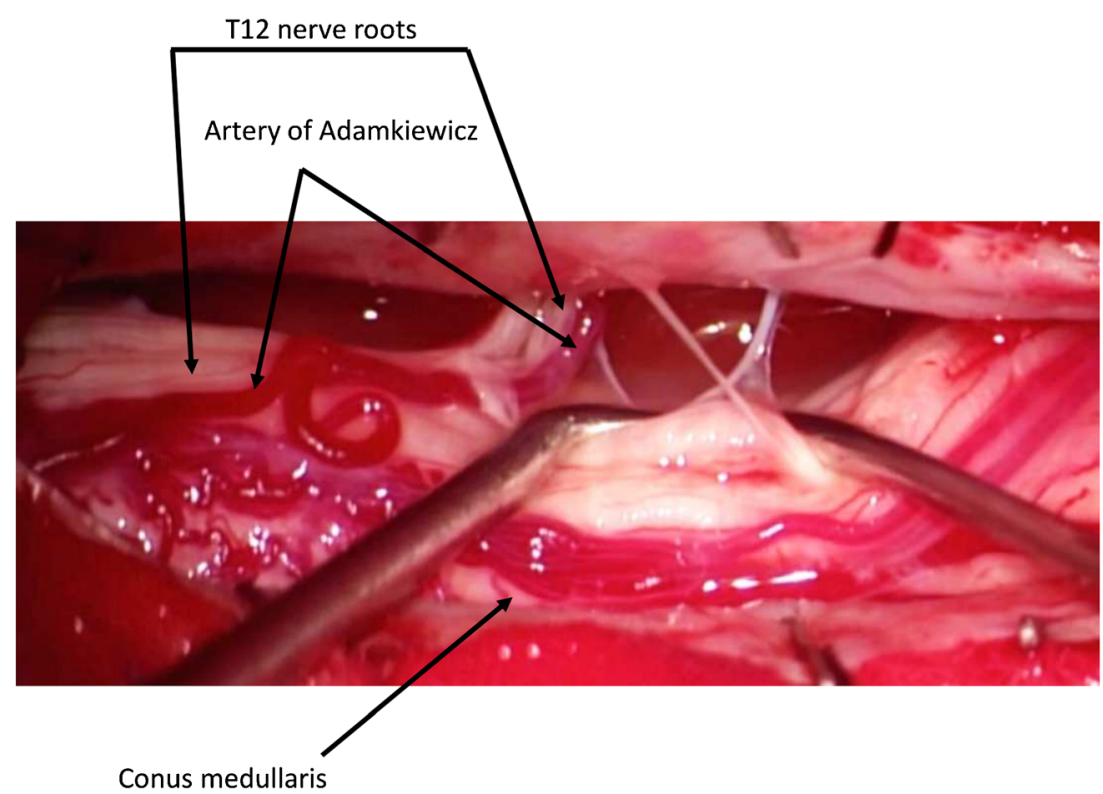

the authors of the original articles were contacted for clarification.

\section{Quality assessment}

The AQUA tool [11] was used by the reviewers to evaluate quality and reliability of the included studies. In brief, the tool was devised to probe for potential risk of bias. Five domains were evaluated in the analysis: (1) objective(s) and subject characteristics, (2) study design, (3) methodology characterization, (4) descriptive anatomy, and (5) reporting of results; and each domain was categorized as either of "Low," "High," or "Unclear" risk of bias. Decision was made that a "No" answer in whichever signaling question within each of the categories arbitrated the domain to be of "High" risk of bias, whereas all answers "Yes" suggested that it presented a "Low"

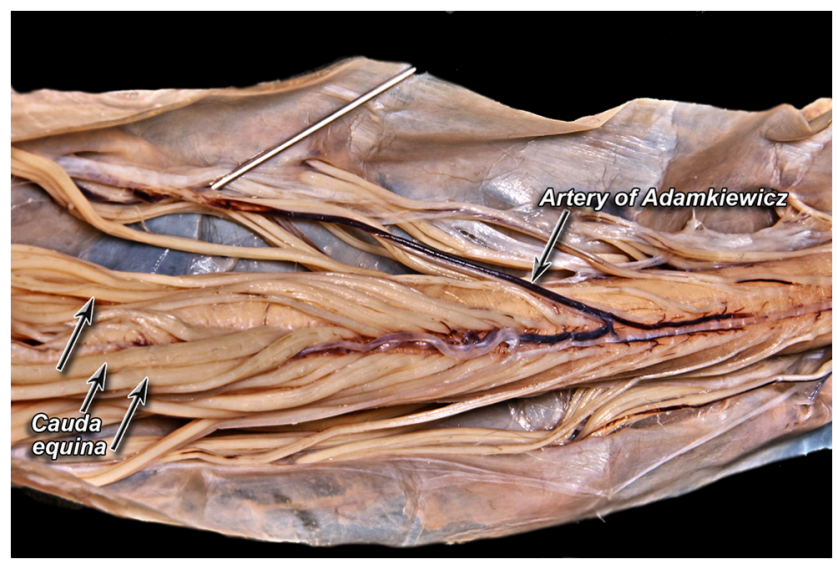

Fig. 3 Cadaveric dissection of the artery of Adamkiewicz risk of bias. "Unclear" option was chosen when the study with incoherent data did not permit for a clear scrutiny.

\section{Statistical analysis}

The prevalence analysis was conducted using MetaXL version 5.8 by EpiGear Pty Ltd. (Wilston, Queensland, Australia). Morphometric analysis using Comprehensive Meta-Analysis version 3.3 yielded the pooled mean diameter of the AKA. Single and multi-categorical pooled prevalence rates were calculated using a random effects model. Heterogeneity was assessed using a chi-squared test and the $I^{2}$ statistic. For the $I^{2}$ statistic, the values of $0-40 \%$ indicated that heterogeneity might not be important; values of 30-60\% could indicate moderate heterogeneity; values of $50-90 \%$ could indicate substantial heterogeneity; and values of 75$100 \%$ indicated considerable heterogeneity. A $p$ value below 0.10 for Cochran's $Q$ suggested significant heterogeneity [12].

An analysis of the subgroups was conducted to determine the source of heterogeneity. The difference between the groups was considered to be insignificant if the confidence intervals (CIs) of specific rates overlapped [13]. Subgroups according to study type, gender, and geographical location were analyzed.

\section{Results \\ Study identification and characteristics of included studies}

The study identification process is presented in Fig. 4. An initial search yielded 747 entries. After thorough analysis, 


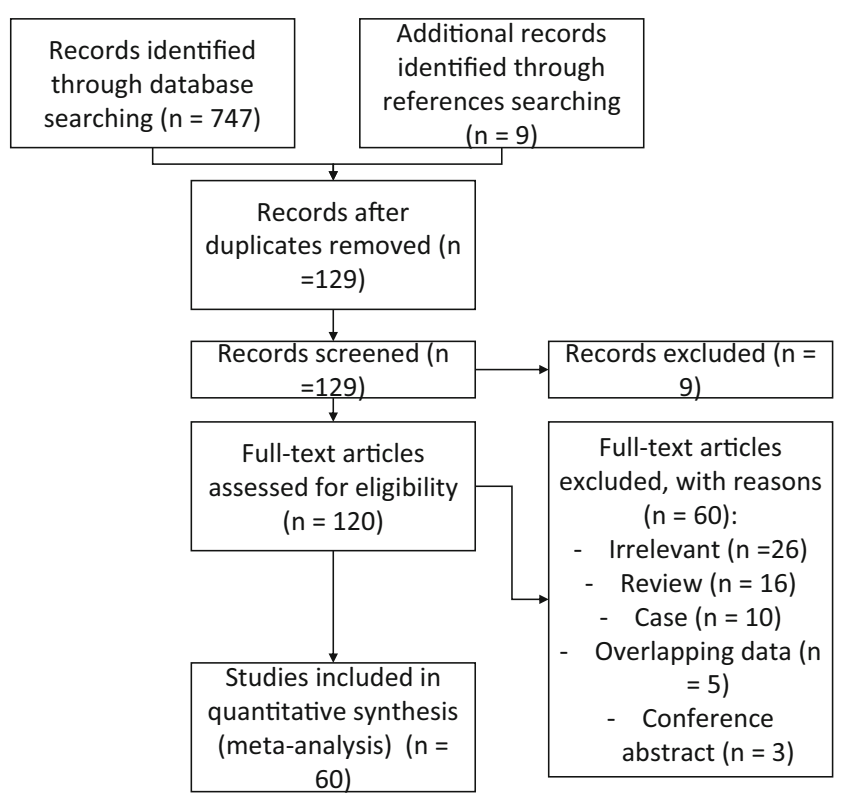

Fig. 4 Flow diagram of included studies

627 entries were excluded. In total, 120 articles were analyzed, and 60 studies were included in this meta-analysis.

The characteristics of the included studies are presented in Table 1. A total of 60 studies (4317 subjects with AKA) published between 1989 [14] and 2017 [15] were included [1-10, 14-62]. The studies originated from North America, Asia and Europe, and from ten different countries.

\section{Quality assessment}

The majority of studies included in this meta-analysis, evaluated by the AQUA tool, revealed domain one (objective(s) and subject characteristics) and domain three (methodology characterization) to be at "High" risk of bias, owing to missing demographic data of the research group and no information regarding experience of the researchers. All studies had a "Low" risk of bias found in domain two (study design) and domain five (reporting of results), and almost all studies had a "Low" risk of bias found in domain four (descriptive anatomy). The AQUA tool evaluation can be found in Table 2.

\section{Prevalence of the artery of Adamkiewicz}

A total of 60 studies ( $n=5437$ subjects) reported data on the prevalence of the AKA. The pooled prevalence estimate (PPE) of the AKA was $84.6 \%$ (95\% CI 79.7-89.0) (Table 3).

The subgroup analysis of gender differences showed that the AKA was slightly more prevalent in males $(93.7 \%$ [95\% CI 83.3-100.0]) than females (90.4\% [95\% CI 68.9-100.0]), although not significantly.
Table 1 Characteristics of included studies

\begin{tabular}{|c|c|c|c|c|}
\hline Study & Country & Type of study & $\begin{array}{l}\text { Number } \\
\text { of } \\
\text { subjects }\end{array}$ & $\begin{array}{l}\% \\
\text { prevalence } \\
\text { of AKA (no } \\
\text { of subjects } \\
\text { with AKA) }\end{array}$ \\
\hline Alleyne 1998 & USA & Cadaveric & 10 & $90.0(9)$ \\
\hline Amako 2011 & Japan & CTA & 110 & $100.0(110)$ \\
\hline Bachet 1996 & France & CTA & 36 & $77.8(28)$ \\
\hline Backes 2008 & Netherlands & MRA & 85 & $100.0(85)$ \\
\hline Biglioli 2004 & Italy & Cadaveric & 51 & $100.0(51)$ \\
\hline Bley 2010 & Germany & MRA & 68 & $88.2(60)$ \\
\hline Boll 2006 & USA & $\begin{array}{l}\text { MDCT } \\
\text { angiogra- } \\
\text { phy }\end{array}$ & 100 & $100.0(100)$ \\
\hline Bowen 1996 & USA & MRA & 6 & $100.0(6)$ \\
\hline Champlin 1994 & USA & DSA & 61 & $32.8(20)$ \\
\hline Charles 2011 & France & DSA & 100 & $96.0(96)$ \\
\hline Fanous 2015 & USA & DSA & 34 & $70.6(24)$ \\
\hline Fereshetian 1989 & USA & DSA & 12 & $75.0(9)$ \\
\hline Furukawa 2010 & Japan & CTA & 37 & $100.0(37)$ \\
\hline Gailloud 2013 & USA & DSA & 50 & $92.0(46)$ \\
\hline Guzinski 2017 & Poland & MSCT & 200 & $21.5(43)$ \\
\hline Heinemann 1998 & Germany & DSA & 46 & $65.2(30)$ \\
\hline Hyodoh 2005 & Japan & MRA & 50 & $84.0(42)$ \\
\hline Hyodoh 2007 & Japan & $\begin{array}{c}\text { MRA (double } \\
\text { subtraction } \\
\text { maximum } \\
\text { intensity } \\
\text { projection) }\end{array}$ & 170 & $82.4(140)$ \\
\hline Hyodoh 2009 & Japan & MRA & 82 & $81.7(67)$ \\
\hline Jaspers 2007 & Netherlands & MRA & 20 & $100.0(20)$ \\
\hline $\begin{array}{l}\text { Kawaharada } \\
2002\end{array}$ & Japan & MRA & 40 & 72.5 (29) \\
\hline $\begin{array}{l}\text { Kawaharada } \\
2004\end{array}$ & Japan & MRA & 120 & 82.5 (99) \\
\hline $\begin{array}{l}\text { Kawaharada } \\
2007\end{array}$ & Japan & MRA & 83 & $85.5(71)$ \\
\hline Kieffer 1989 & France & Arteriography & 45 & $88.9(40)$ \\
\hline Kieffer 2002 & France & Arteriography & 480 & 87.3 (419) \\
\hline Koshino 1999 & Japan & Cadaveric & 102 & $88.2(90)$ \\
\hline Kovacs 2009 & Germany & $\mathrm{CT}$ & 51 & $70.6(36)$ \\
\hline $\begin{array}{l}\text { Kroszczynski } \\
2013\end{array}$ & USA & Cadaveric & 24 & $95.8(23)$ \\
\hline Kudo 2003 & Japan & MDCT & 19 & $68.4(13)$ \\
\hline Matsuda 2010 & Japan & $\begin{array}{l}\text { MRA and } \\
\text { CTA }\end{array}$ & 50 & $94.0(47)$ \\
\hline Matsuda 2010a & Japan & $\begin{array}{l}\text { MRA and } \\
\text { CTA }\end{array}$ & 60 & $80.0(48)$ \\
\hline Melissano 2009 & Italy & MDCT & 67 & $67.2(45)$ \\
\hline Mordasini 2012 & Switzerland & MRA & 24 & $83.3(20)$ \\
\hline Morishita 2003 & Japan & Cadaveric & 55 & $100.0(55)$ \\
\hline Murthy 2010 & USA & $\begin{array}{l}\text { Spinal } \\
\text { angiogra- } \\
\text { phy }\end{array}$ & 248 & 46.4 (115) \\
\hline Nakayama 2008 & Japan & CTA & 80 & $56.3(45)$ \\
\hline
\end{tabular}


Table 1 (continued)

\begin{tabular}{|c|c|c|c|c|}
\hline Study & Country & Type of study & $\begin{array}{l}\text { Number } \\
\text { of } \\
\text { subjects }\end{array}$ & $\begin{array}{l}\% \\
\text { prevalence } \\
\text { of AKA (no. } \\
\text { of subjects } \\
\text { with AKA) }\end{array}$ \\
\hline Nijenhuis 2004 & Netherlands & MRA & 8 & $100.0(8)$ \\
\hline Nijenhuis 2007 & Netherlands & $\begin{array}{c}\text { MRA and } \\
\text { CTA }\end{array}$ & 39 & $100.0(39)$ \\
\hline Nijenhuis 2007a & Netherlands & MRA & 60 & $100.0(60)$ \\
\hline Nishida 2014 & Japan & $\mathrm{CT}$ & 33 & $75.8(25)$ \\
\hline Nishii 2013 & Japan & CTA & 160 & $81.9(131)$ \\
\hline Nojiri 2007 & Japan & CTA & 27 & $100.0(27)$ \\
\hline Ogino 2006 & Japan & MRA & 92 & $70.7(65)$ \\
\hline Ou 2007 & France & CTA & 40 & $95.0(38)$ \\
\hline Polaczek 2014 & Poland & Cadaveric & 28 & $100.0(28)$ \\
\hline $\begin{array}{l}\text { Rodriguez-Baeza } \\
\quad 1991\end{array}$ & Spain & Cadaveric & 30 & $100.0(30)$ \\
\hline Schurink 2007 & Netherlands & MRA & 9 & $100.0(9)$ \\
\hline $\begin{array}{l}\text { Sukeeyamonon } \\
2010\end{array}$ & Thailand & $\begin{array}{l}\text { MDCT } \\
\text { angiogra- } \\
\text { phy }\end{array}$ & 73 & $71.2(52)$ \\
\hline Takagi 2015 & Japan & $\begin{array}{l}\text { MRA and } \\
\text { MDCTA }\end{array}$ & 117 & 89.7 (105) \\
\hline Takase 2002 & Japan & MDCT & 70 & $90.0(63)$ \\
\hline Takase 2007 & Japan & MDCT & 10 & $90.0(9)$ \\
\hline Tanaka 2016 & Japan & $\begin{array}{c}\text { MRA and } \\
\text { CTA }\end{array}$ & 1252 & 87.5 (1096) \\
\hline Uotani 2008 & Japan & CTA & 32 & $78.1(25)$ \\
\hline Utsunomiya 2008 & Japan & CTA & 80 & $62.5(50)$ \\
\hline Williams 1991 & USA & $\begin{array}{l}\text { Retrograde } \\
\text { femoral } \\
\text { artery } \\
\text { catherizati- } \\
\text { on }\end{array}$ & 47 & $55.3(26)$ \\
\hline Yamada 2000 & Japan & MRA & 26 & $69.2(18)$ \\
\hline Yingbin 2013 & China & MDCT & 217 & $55.8(121)$ \\
\hline Yoshioka 2003 & Japan & $\begin{array}{l}\text { MRA and } \\
\text { CTA }\end{array}$ & 30 & $90.0(27)$ \\
\hline Yoshioka 2006 & Japan & $\begin{array}{c}\text { MRA and } \\
\text { CTA }\end{array}$ & 30 & 96.7 (29) \\
\hline Zhao 2009 & China & MDCTA & 51 & $35.3(18)$ \\
\hline
\end{tabular}

Seven cadaveric studies $(n=300)$ yielded the highest PPE of the AKA (97.5\% [95\% CI 92.4-100.0]) among the different study types. This was followed by MRA, CTA, and DSA studies with PPEs of $88.3 \%, 88.1 \%$, and $75.4 \%$, respectively (Table 3).

The subgroup analysis of geographical origin showed that the AKA was most prevalent in the Netherlands, with a PPE of 99.4\% (95\% CI 98.2-100.0); France with a PPE of $89.8 \%$ (95\% CI 83.8-94.6); and Japan, with a PPE of 85.3 (95\% CI 81.0-89.2). It was least prevalent in the USA, with a PPE of $79.5 \%$ (95\% CI 57.0-95.7).

\section{Number of arteries of Adamkiewicz per patient}

An analysis of 20 studies ( $n=1329$ subjects with AKAs) showed that the majority of patients $(87.4 \%$ [95\% CI 83.4 91.9]) had one AKA. Patients presented with two AKAs in $11.3 \%$ (95\% CI 7.5-15.8) of cases, three AKAs in 0.8\% (95\% CI $0.0-2.5$ ) of cases, and four AKAs in $0.5 \%$ (95\% CI 0.0 1.6) of cases.

In patients with two AKAs, the majority $(73.3 \%$ [95\% CI 47.3-93.4]) presented unilaterally as duplications. A total of 26.7\% (95\% CI 6.6-52.7; $I^{2} 66.2 \%, 95 \%$ CI 12.0-87.0; $p=$ 0.019 ) of patients with two AKAs had bilateral configuration.

\section{Origin of the artery of Adamkiewicz}

A total of 56 studies ( $n=3316$ patients with AKA) analyzed the side of origin of AKA. The results showed that $76.6 \%$ (95\% CI 73.2-79.9) of AKAs originated from the left side, while $23.4 \%$ (95\% CI $20.1-26.8 ; I^{2} 78.5 \%$, 95\% CI $72.5-$ $83.2 ; p<0.001)$ from the right side. The analysis of 43 studies ( $n=2834$ patients with AKA) showed that $89 \%$ of arteries originated between T8 and L1 (Table 4). AKA most frequently originated at the level of T9 with PPE of $22.2 \%(95 \%$ CI 18.9-25.4), followed by T10 and T11 with PPE of $21.7 \%$ (95\% CI 18.5-25.0) and $18.7 \%$ (95\% CI 15.6-21.8), respectively.

\section{Continuity of the artery of Adamkiewicz}

A total of seven studies ( $n=375$ patients with AKAs) were included in an analysis of the continuity of the AKA from the aorta to the anterior spinal artery. The results showed that AKA continued from the aorta to the anterior spinal artery in $71.3 \%$ of patients (95\% CI $45.8-91.6 ; I^{2} 95.6 \%, 95 \%$ CI 92.8-97.2; $p<0.001)$.

\section{Morphometric analysis of the artery of Adamkiewicz}

Five studies ( $n=324$ patients with AKA) analyzed the morphometric data of the AKA. The analysis showed a pooled mean diameter of $1.09 \mathrm{~mm}\left(95 \%\right.$ CI $0.69-1.50 ; I^{2} 36.2 \%$; $p<0.001)$.

\section{Discussion}

Because the AKA originates from the lumbar arteries, it may be prudent to preserve the blood flow from the lumbar arteries when a thoracoabdominal aortic repair is planned [5, 63]. Concomitant or previous abdominal aortic repair and extensive thoracic aorta exclusion by means of multiple stent grafts are associated with a significantly higher risk of paraplegia [64]. After the interruption of most of the 
Table 2 The AQUA tool-tabular display

\begin{tabular}{|c|c|c|c|c|c|}
\hline \multirow[t]{2}{*}{ Study } & \multicolumn{5}{|l|}{ Risk of bias } \\
\hline & $\begin{array}{l}\text { Objective(s) and study } \\
\text { characteristics }\end{array}$ & $\begin{array}{l}\text { Study } \\
\text { design }\end{array}$ & $\begin{array}{l}\text { Methodology } \\
\text { characterization }\end{array}$ & $\begin{array}{l}\text { Descriptive } \\
\text { anatomy }\end{array}$ & $\begin{array}{l}\text { Reporting of } \\
\text { results }\end{array}$ \\
\hline Alleyne 1998 & High & Low & High & Low & Low \\
\hline Amako 2011 & Low & Low & High & Low & Low \\
\hline Bachet 1996 & High & Low & High & High & Low \\
\hline Backes 2008 & High & Low & High & Low & Low \\
\hline Biglioli 2004 & Low & Low & High & High & Low \\
\hline Bley 2010 & Low & Low & High & Low & Low \\
\hline Boll 2006 & High & Low & High & High & Low \\
\hline Bowen 1996 & High & Low & High & Low & Low \\
\hline Champlin 1994 & High & Low & High & Low & Low \\
\hline Charles 2011 & High & Low & High & Low & Low \\
\hline Fanous 2015 & High & Low & High & Low & Low \\
\hline Fereshetian 1989 & High & Low & High & Low & Low \\
\hline Furukawa 2010 & High & Low & High & Low & Low \\
\hline Gailloud 2013 & High & Low & High & Low & Low \\
\hline Guzinski 2017 & High & Low & High & Low & Low \\
\hline Heinemann 1998 & High & Low & High & Low & Low \\
\hline Hyodoh 2005 & High & Low & High & High & Low \\
\hline Hyodoh 2007 & High & Low & High & Low & Low \\
\hline Hyodoh 2009 & High & Low & High & High & Low \\
\hline Jaspers 2007 & High & Low & High & Low & Low \\
\hline Kawaharada 2002 & High & Low & High & Low & Low \\
\hline Kawaharada 2004 & High & Low & High & Low & Low \\
\hline Kawaharada 2007 & High & Low & High & Low & Low \\
\hline Kieffer 1989 & High & Low & High & High & Low \\
\hline Kieffer 2002 & High & Low & High & Low & Low \\
\hline Koshino 1999 & High & Low & High & Low & Low \\
\hline Kovacs 2009 & High & Low & High & Low & Low \\
\hline Kroszczynski 2013 & High & Low & High & Low & Low \\
\hline Kudo 2003 & High & Low & High & Low & Low \\
\hline Matsuda 2010 & High & Low & High & High & Low \\
\hline Matsuda 2010a & High & Low & High & High & Low \\
\hline Melissano 2009 & High & Low & Low & High & Low \\
\hline Mordasini 2012 & High & Low & Low & High & Low \\
\hline Morishita 2003 & High & Low & High & Low & Low \\
\hline Murthy 2010 & Unclear & Low & High & Low & Low \\
\hline Nakayama 2008 & High & Low & Low & Low & Low \\
\hline Nijenhuis 2004 & High & Low & Unclear & Low & Low \\
\hline Nijenhuis 2007 & High & Low & High & Low & Low \\
\hline Nijenhuis 2007a & High & Low & High & Low & Low \\
\hline Nishida 2014 & High & Low & Low & High & Low \\
\hline Nishii 2013 & High & Low & Low & High & Low \\
\hline Nojiri 2007 & High & Low & High & Low & Low \\
\hline Ogino 2006 & High & Low & High & High & Low \\
\hline Ou 2007 & High & Low & Unclear & High & Low \\
\hline Polaczek 2014 & High & Low & High & Low & Low \\
\hline $\begin{array}{l}\text { Rodriguez-Baeza } \\
\quad 1991\end{array}$ & High & Low & High & Low & Low \\
\hline
\end{tabular}


Table 2 (continued)

\begin{tabular}{|c|c|c|c|c|c|}
\hline \multirow[t]{2}{*}{ Study } & \multicolumn{5}{|l|}{ Risk of bias } \\
\hline & $\begin{array}{l}\text { Objective(s) and study } \\
\text { characteristics }\end{array}$ & $\begin{array}{l}\text { Study } \\
\text { design }\end{array}$ & $\begin{array}{l}\text { Methodology } \\
\text { characterization }\end{array}$ & $\begin{array}{l}\text { Descriptive } \\
\text { anatomy }\end{array}$ & $\begin{array}{l}\text { Reporting of } \\
\text { results }\end{array}$ \\
\hline Schurink 2007 & High & Low & High & Low & Low \\
\hline Sukeeyamonon 2010 & High & Low & Low & High & Low \\
\hline Takagi 2015 & High & Low & Low & Low & Low \\
\hline Takase 2002 & High & Low & High & Low & Low \\
\hline Takase 2007 & High & Low & High & High & Low \\
\hline Tanaka 2016 & High & Low & High & Low & Low \\
\hline Uotani 2008 & High & Low & High & Low & Low \\
\hline Utsunomiya 2008 & High & Low & High & Low & Low \\
\hline Williams 1991 & High & Low & High & Low & Low \\
\hline Yamada 2000 & High & Low & High & Low & Low \\
\hline Yingbin 2013 & High & Low & High & Low & Low \\
\hline Yoshioka 2003 & High & Low & High & Low & Low \\
\hline Yoshioka 2006 & High & Low & High & Low & Low \\
\hline Zhao 2009 & High & Low & High & Low & Low \\
\hline
\end{tabular}

intercostal and lumbar arteries, the residual collateral blood supply is marginal, and in some cases, the spinal cord may become extremely prone to injury due to arterial hypotension or low cardiac output from any cause [65]. During aortic repair, preservation, reattachment, or reconstruction of the intercostal or lumbar arteries can maintain the blood supply to the spinal cord $[66,67]$. Depending on the number of intercostal or lumbar arteries that require reconstruction, the ischemic duration may be prolonged during reconstruction. In our study, in patients with an AKA present, $11.3 \%$ had two AKAs, with bilateral AKAs present in $26.7 \%$ of these patients. The preoperative identification of the AKA and its anatomical characteristics allows for superior surgical planning, such that the surgical time and postoperative spinal complication risk are decreased [31]. Therefore, AKA identification is of interest for surgeons aiming to reconstruct intercostal or lumbar arteries in order to prevent postoperative spinal ischemic complications [3].

With respect to the continuity between the radicular arteries (including the AKA) and the anterior spinal arteries, the AKA continued from the aorta to the anterior spinal artery in $71.3 \%$ of the patients in our study. When this continuity is present, blood may drain away from the spinal cord through the anterior spinal arteries and the radicular arteries, acting as stealing channels by rerouting the blood to be distal to an aortic obstruction [5]. During aortic crossclamping, back-bleeding from the ostia of the posterior intercostal and lumbar arteries may be a clinical

Table 3 Overall prevalence of AKA

\begin{tabular}{|c|c|c|c|c|c|}
\hline Subgroup & & $\begin{array}{l}\text { Number of studies } \\
\text { (number of subjects) }\end{array}$ & $\begin{array}{l}\text { Pooled prevalence } \\
\text { of AKA: } \%(95 \% \mathrm{CI})\end{array}$ & $\begin{array}{l}I^{2} \% \\
(95 \% \mathrm{CI})\end{array}$ & Cochran's $Q, p$ value \\
\hline Overall & & $60(5437)$ & $84.6(79.7-89.0)$ & $95.3(94.5-95.9)$ & $<0.001$ \\
\hline \multirow[t]{2}{*}{ Gender } & Males & $15(515)$ & 93.7 (83.3-100.0) & $94.0(91.6-95.7)$ & $<0.001$ \\
\hline & Females & $14(345)$ & $90.4(68.9-100.0)$ & 96.4 (95.2-97.4) & $<0.001$ \\
\hline \multirow[t]{4}{*}{ Type of study } & Cadaveric & $7(300)$ & $97.5(92.4-100.0)$ & $72.2(38.8-87.1)$ & 0.001 \\
\hline & CTA & $9(602)$ & $88.1(74.0-97.6)$ & $94.4(91.4-96.4)$ & $<0.001$ \\
\hline & MRA & $16(943)$ & $88.3(81.9-93.4)$ & $85.1(77.3-90.3)$ & $<0.001$ \\
\hline & DSA & $6(303)$ & 75.4 (49.1-94.9) & $94.9(91.2-97.0)$ & $<0.001$ \\
\hline \multirow[t]{4}{*}{ Country of origin } & Japan & 27 (3017) & $85.3(81.0-89.2)$ & 87.5 (83.0-90.8) & $<0.001$ \\
\hline & USA & $10(592)$ & $79.5(57.0-95.7)$ & 96.3 (94.7-97.4) & $<0.001$ \\
\hline & France & $5(701)$ & 89.8 (83.8-94.6) & $69.0(20.4-87.9)$ & 0.012 \\
\hline & Netherlands & $6(221)$ & $99.4(98.2-100.0)$ & $0.0(0.0-0.0)$ & 0.972 \\
\hline
\end{tabular}


manifestation of such rerouting of blood when continuity between the AKA and the anterior spinal arteries is present. This steal phenomenon may further worsen spinal cord ischemia, causing irreversible neurological injuries if the ischemia time is longer than 20 to $30 \mathrm{~min}$ [68].

The detection of the AKA can be difficult because of the various possible levels of origins of the artery, its small size, the amount of time needed to obtain the angiogram, and complications that can occur during surgical procedures $[14,26]$. In our study, the pooled mean diameter of the AKA was $1.09 \mathrm{~mm}$. Various techniques have been devised to preoperatively identify the location and anatomy of the AKA, such as CTA [55], MRA [7], and DSA [9]. These techniques can be used to identify both the level and the laterality of the artery, which can affect a surgeon's approach to an aneurysm or spinal lesion. We have included three DSA images with injected contrast into left radicular artery at the level of T4 (Fig. 5), T8 (Fig. 6), and T11 (Fig. 7). In our meta-analysis, cadaveric studies had the highest prevalence of an AKA (97.5\%), and among the different imaging modalities, MRA and CTA had the highest prevalence rates ( $88.3 \%$ and $88.1 \%$, respectively), while DSA had the lowest prevalence rate (75.4\%). In spite of its apparent success in detecting an AKA, MRA has been shown to be inferior to DSA in terms of evaluating vessel continuity, sharpness, and background homogeneity [7]. Furthermore, compared with CTA, a more limited field of view is a major disadvantage of MRA [61]. As a result, MRA may fail to depict the clinically important collateral vessels to the AKA in some patients, when a collateral source

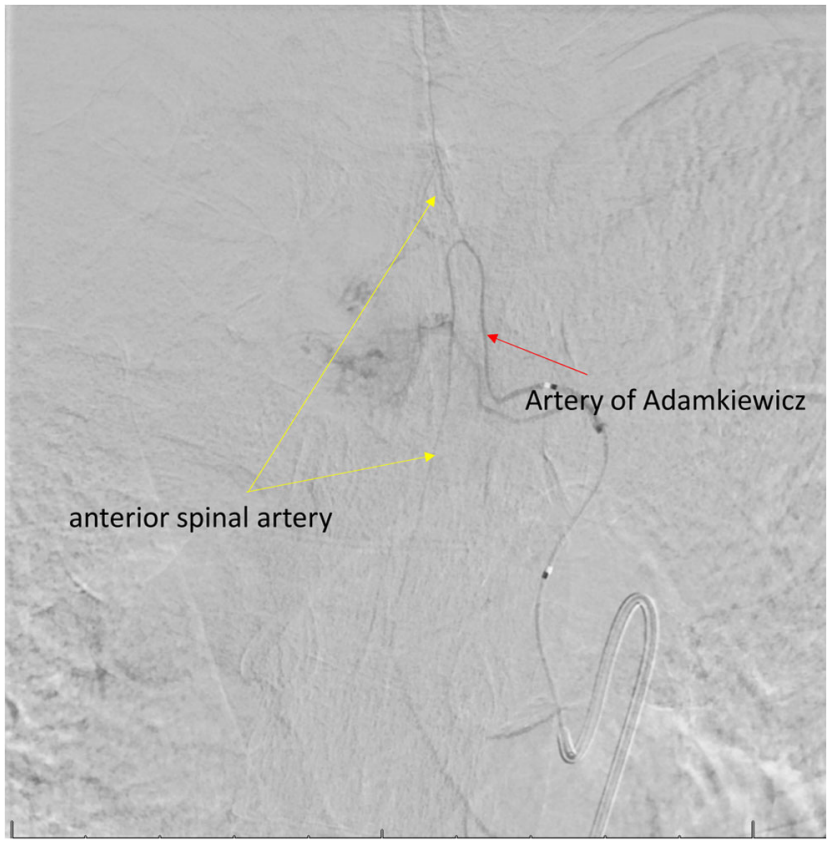

Fig. 5 Digital subtraction angiography image of the artery of Adamkiewicz from left $\mathrm{T} 4$ radicular artery injection 


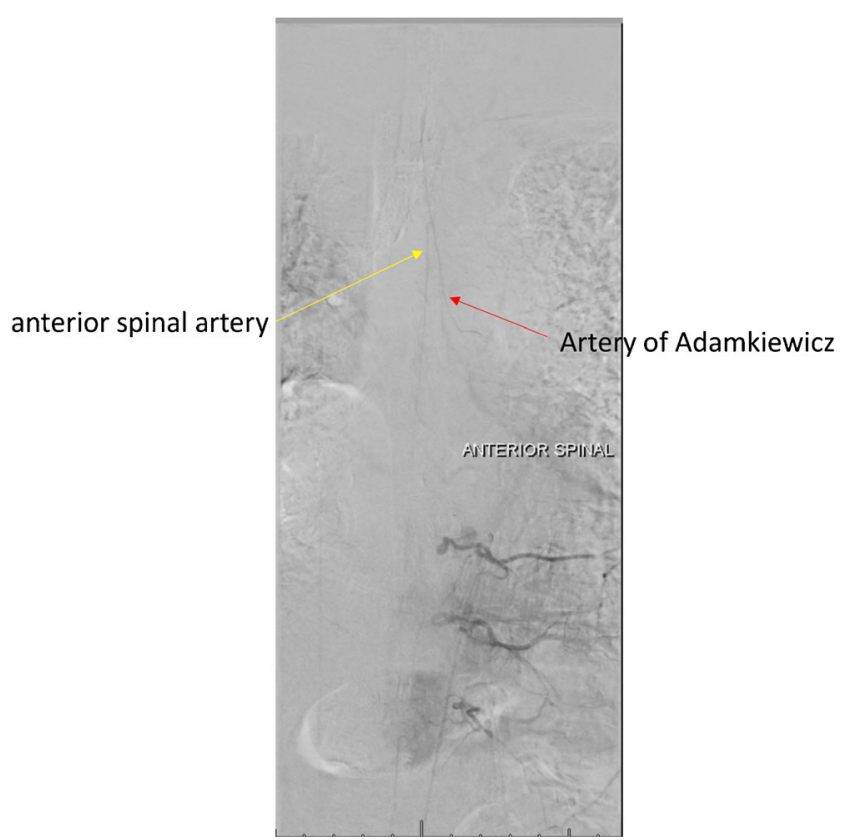

Fig. 6 Digital subtraction angiography image of the artery of Adamkiewicz from left $\mathrm{T} 8$ radicular artery injection

is the internal thoracic artery or the thoracodorsal artery [69]. Despite DSA studies reporting a lower prevalence rate of the AKA than MRA and CTA in our meta-analysis, DSA remains the "gold standard" for identifying spinal cord vasculature as it is both safe and efficient [9]. A possible reason for this discrepancy could be the small number of patients included in our DSA analysis as compared to the number of patients included in our MRA and CTA analyses.

Future studies should examine the blood supply and the collateral circulation of the spinal cord in the presence of degenerative atherosclerotic or dissecting aneurysm, or after a surgical or endovascular aortic procedure. In these patients, the disease and the surgical procedure may occlude several segmental arteries and promote collateral vessels enlargement, significantly altering the normal patterns of blood supply to the spinal cord [5].

Our meta-analysis was limited by the high amount of heterogeneity between the studies. However, the number of included studies and their large sample sizes mitigate this limitation. As cadaveric dissection is the gold standard for anatomical considerations, more cadaveric studies should assess prevalence of AKA, especially performed on subjects poorly represented in our meta-analysis, such as Africa, South America, and Oceania.

Because of the lower prevalence of AKA in radiological studies, surgeons should keep in mind that these results might be false negative. In this case, the risk of iatrogenic injury to the AKA during thoracolumbar surgical procedures is increased. More accurate imaging methods should be developed to assess the true prevalence of AKA.

To ensure spinal cord safety, preoperative AKA identification and its subsequent reconstruction or preservation are effective adjuncts for more secure protection of the spinal cord, along with other adequate management strategies.
Fig. 7 Digital subtraction angiography image of the artery of Adamkiewicz from left T11 radicular artery injection

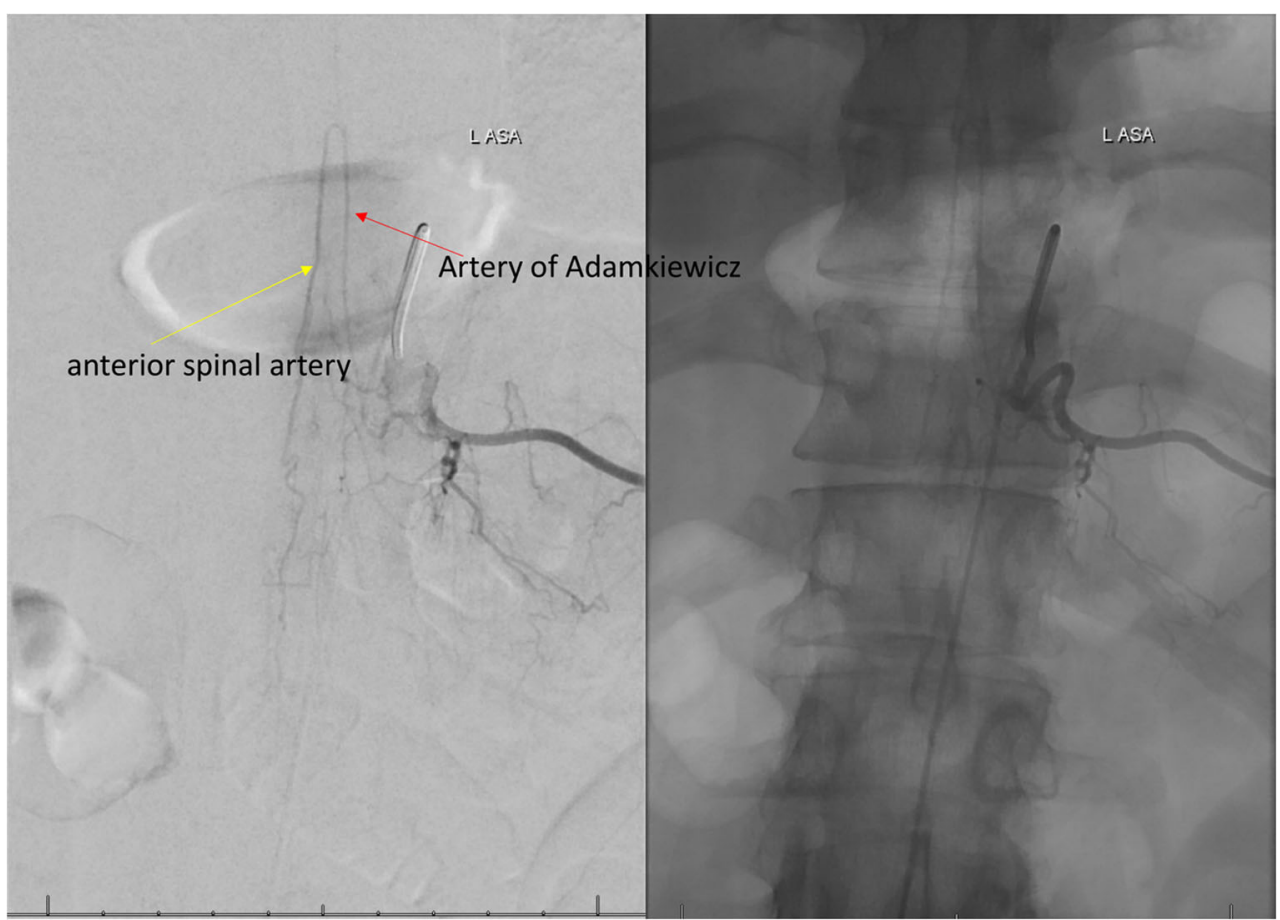




\section{Conclusions}

Our main findings revealed that the AKA was found to be present in the vast majority of the general population $(84.6 \%)$, most often as a single vessel $(87.4 \%)$ originating between T8 and L1 (89\%) on the left side (76.6\%). Based on our anatomical findings, we recommend that efforts should be made to identify and subsequently reconstruct or preserve the AKA to prevent postoperative neurological deficit due to spinal cord ischemia in vascular and endovascular surgical procedures in the thoracolumbar spinal cord.

Acknowledgements KAT was supported by the Polish Ministry of Higher Education grant for young scientists.

Funding The authors received no financial support for the research, authorship, and/or publication of this article.

\section{Compliance with ethical standards}

Conflict of interest The authors declare that they have no conflict of interest.

Ethical approval For this type of meta-analysis study formal consent is not required.

\section{Informed consent NA}

Open Access This article is distributed under the terms of the Creative Commons Attribution 4.0 International License (http:// creativecommons.org/licenses/by/4.0/), which permits unrestricted use, distribution, and reproduction in any medium, provided you give appropriate credit to the original author(s) and the source, provide a link to the Creative Commons license, and indicate if changes were made.

\section{References}

1. Sukeeyamanon W, Siriapisith T, Wasinrat J (2010) Preoperative localization of Adamkiewicz arteries and their origins by using MDCT angiography. J Med Assoc Thail 93:1430-1436

2. Ogino H, Sasaki H, Minatoya K, Matsuda H, Yamada N, Kitamura S (2006) Combined use of Adamkiewicz artery demonstration and motor-evoked potentials in descending and thoracoabdominal repair. Ann Thorac Surg 82:592-596. https://doi.org/10.1016/j. athoracsur.2006.03.041

3. Takagi H, Ota H, Natsuaki Y, Komori Y, Ito K, Saiki Y, Takase K (2015) Identifying the Adamkiewicz artery using 3-T time-resolved magnetic resonance angiography: its role in addition to multidetector computed tomography angiography. Jpn J Radiol 33:749-756. https://doi.org/10.1007/s11604-015-0490-6

4. Gailloud P (2013) The artery of von Haller: a constant anterior radiculomedullary artery at the upper thoracic level. Neurosurgery 73:1034-1043. https://doi.org/10.1227/NEU.0000000000000163

5. Biglioli P, Roberto M, Cannata A, Parolari A, Fumero A, Grillo F, Maggioni M, Coggi G, Spirito R (2004) Upper and lower spinal cord blood supply: the continuity of the anterior spinal artery and the relevance of the lumbar arteries. J Thorac Cardiovasc Surg 127: 1188-1192. https://doi.org/10.1016/j.jtcvs.2003.11.038

6. Koshino T, Murakami G, Morishita K, Mawatari T, Abe T (1999) Does the Adamkiewicz artery originate from the larger segmental arteries? J Thorac Cardiovasc Surg 117:898-905. https://doi.org/ 10.1016/S0022-5223(99)70369-7

7. Yamada N, Okita Y, Minatoya K, Tagusari O, Ando M, Takamiya M, Kitamura S (2000) Preoperative demonstration of the Adamkiewicz artery by magnetic resonance angiography in patients with descending or thoracoabdominal aortic aneurysms. Eur J Cardiothorac Surg 18:104-111

8. Yoshioka K, Niinuma H, Ohira A, Nasu K, Kawakami T, Sasaki M, Kawazoe K (2003) MR angiography and CT angiography of the artery of Adamkiewicz: noninvasive preoperative assessment of thoracoabdominal aortic aneurysm. RadioGraphics 23:12151225. https://doi.org/10.1148/rg.235025031

9. Fanous AA, Lipinski LJ, Krishna C, Roger EP, Siddiqui AH, Levy EI, Leonardo J, Pollina J (2015) The impact of preoperative angiographic identification of the artery of Adamkiewicz on surgical decision making in patients undergoing thoracolumbar corpectomy. Spine (Phila Pa 1976) 40:1194-1199. https://doi.org/10.1097/BRS. 0000000000000909

10. Nijenhuis RJ, Leiner T, Cornips EMJ, Wilmink JT, Jacobs MJ, van Engelshoven JMA, Backes WH (2004) Spinal cord feeding arteries at MR angiography for thoracoscopic spinal surgery: feasibility study and implications for surgical approach. Radiology 233:541547. https://doi.org/10.1148/radiol.2331031672

11. Henry BM, Tomaszewski KA, Ramakrishnan PK, Roy J, Vikse J, Loukas M, Tubbs RS, Walocha JA (2017) Development of the anatomical quality assessment (AQUA) tool for the quality assessment of anatomical studies included in meta-analyses and systematic reviews. Clin Anat 30:6-13. https://doi.org/10.1002/ca.22799

12. Higgins J, Green S (eds) (2011) Cochrane Handbook for Systematic Reviews of Interventions Version 5.1.0 [updated March 2011]

13. Henry BM, Tomaszewski KA, Walocha JA (2016) Methods of evidence-based anatomy: a guide to conducting systematic reviews and meta-analysis of anatomical studies. Ann Anat 205:16-21. https://doi.org/10.1016/j.aanat.2015.12.002

14. Fereshetian A, Kadir S, Kaufman SL, Mitchell SE, Murray RR, Kinnison ML, Williams GM (1989) Digital subtraction spinal cord angiography in patients undergoing thoracic aneurysm surgery. Cardiovasc Intervent Radiol 12:7-9

15. Guziński M, Bryl M, Ziemińska K, Wolny K, Sąsiadek M, Garcarek J (2017) Detection of the Adamkiewiczartery in computed tomography of the thorax and abdomen. Adv Clin Exp Med 26: 31-37. https://doi.org/10.17219/acem/62788

16. Alleyne CH, Cawley CM, Shengelaia GG, Barrow DL (1998) Microsurgical anatomy of the artery of Adamkiewicz and its segmental artery. J Neurosurg 89:791-795. https://doi.org/10.3171/jns. 1998.89.5.0791

17. Amako M, Yamamoto Y, Nakamura K et al (2011) Preoperative visualization of the artery of Adamkiewicz by dual-phase CT angiography in patients with aortic aneurysm. Kurume Med J 58:117-125

18. Bachet J, Guilmet D, Rosier J et al (1996) Protection of the spinal cord during surgery of thoraco-abdominal aortic aneurysms. Eur J Cardiothorac Surg 10:817-825

19. Backes WH, Nijenhuis RJ, Mess WH, Wilmink FA, Schurink GWH, Jacobs MJ (2008) Magnetic resonance angiography of collateral blood supply to spinal cord in thoracic and thoracoabdominal aortic aneurysm patients. J Vasc Surg 48:261271. https://doi.org/10.1016/j.jvs.2008.03.015

20. Bley TA, Duffek CC, François CJ, Schiebler ML, Acher CW, Mell M, Grist TM, Reeder SB (2010) Presurgical localization of the artery of Adamkiewicz with time-resolved 3.0-T MR angiography. Radiology 255:873-881. https://doi.org/10.1148/radiol.10091304 
21. Boll DT, Bulow H, Blackham KA, Aschoff AJ, Schmitz BL (2006) MDCT angiography of the spinal vasculature and the artery of Adamkiewicz. AJR Am J Roentgenol 187:1054-1060. https://doi. org/10.2214/AJR.05.0562

22. Bowen BC, DePrima S, Pattany PM, Marcillo A, Madsen P, Quencer RM (1996) MR angiography of normal intradural vessels of the thoracolumbar spine. AJNR Am J Neuroradiol 17:483-494

23. Champlin AM, Rael J, Benzel EC, Kesterson L, King JN, Orrison WW, Mirfakhraee M (1994) Preoperative spinal angiography for lateral extracavitary approach to thoracic and lumbar spine. AJNR Am J Neuroradiol 15:73-77

24. Charles YP, Barbe B, Beaujeux R, Boujan F, Steib JP (2011) Relevance of the anatomical location of the Adamkiewicz artery in spine surgery. Surg Radiol Anat 33:3-9. https://doi.org/10.1007/ s00276-010-0654-0

25. Furukawa K, Kamohara K, Nojiri J, Egashira Y, Okazaki Y, Kudo S, Morita S (2010) Operative strategy for descending and thoracoabdominal aneurysm repair with preoperative demonstration of the Adamkiewicz artery. Ann Thorac Surg 90:1840-1846. https://doi.org/10.1016/j.athoracsur.2010.07.056

26. Heinemann MK, Brassel F, Herzog Tet al (1998) The role of spinal angiography in operations on the thoracic aorta: myth or reality? Ann Thorac Surg 65:346-351

27. Hyodoh H, Kawaharada N, Akiba H, Tamakawa M, Hyodoh K, Fukada J, Morishita K, Hareyama M (2005) Usefulness of preoperative detection of artery of Adamkiewicz with dynamic contrastenhanced MR angiography. Radiology 236:1004-1009. https://doi. org/10.1148/radiol.2363040911

28. Hyodoh H, Shirase R, Akiba H, Tamakawa M, Hyodoh K, Yama N, Shonai T, Hareyama M (2007) Double-subtraction maximum intensity projection MR angiography for detecting the artery of Adamkiewicz and differentiating it from the drainage vein. $\mathrm{J}$ Magn Reson Imaging 26:359-365. https://doi.org/10.1002/jmri. 21024

29. Hyodoh H, Shirase R, Kawaharada N et al (2009) MR angiography for detecting the artery of Adamkiewicz and its branching level from the aorta. Magn Reson Med Sci 8:159-164

30. Jaspers K, Nijenhuis RJ, Backes WH (2007) Differentiation of spinal cord arteries and veins by time-resolved MR angiography. J Magn Reson Imaging 26:31-40. https://doi.org/10.1002/jmri. 20940

31. Kawaharada N, Morishita K, Fukada J, Yamada A, Muraki S, Hyodoh H, Abe T (2002) Thoracoabdominal or descending aortic aneurysm repair after preoperative demonstration of the Adamkiewicz artery by magnetic resonance angiography. Eur J Cardiothorac Surg 21:970-974

32. Hachiro Y, Kawaharada N, Morishita K, Fukada J, Fujisawa Y, Kurimoto Y, Abe T (2004) Thoracoabdominal aortic aneurysm repair after detection of the Adamkiewicz artery by magnetic resonance angiography; a way to shorten operating time and improve outcome. Kyobu Geka 57:280-283

33. Kawaharada N, Morishita K, Kurimoto Y et al (2007) Spinal cord ischemia after elective endovascular stent-graft repair of the thoracic aorta. Eur J Cardiothorac Surg 31:998-1003. https://doi.org/10. 1016/j.ejcts.2007.01.069

34. Kieffer E, Richard T, Chiras J, Godet G, Cormier E (1989) Preoperative spinal cord arteriography in aneurysmal disease of the descending thoracic and thoracoabdominal aorta: preliminary results in 45 patients. Ann Vasc Surg 3:34-46. https://doi.org/10. 1016/S0890-5096(06)62382-0

35. Kieffer E, Fukui S, Chiras J, Koskas F, Bahnini A, Cormier E (2002) Spinal cord arteriography: a safe adjunct before descending thoracic or thoracoabdominal aortic aneurysmectomy. J Vasc Surg $35: 262-268$

36. Kovács A, Schiller W, Gerhards HM, Welz A, Willinek W, Schild H, Urbach H, Flacke S (2009) Visualization of the Adamkiewicz artery in patients with acute Stanford A dissections: a prospective 64-row multi-detector CT study. Rofo 181:870-874. https://doi.org/ $10.1055 / \mathrm{s}-0028-1109441$

37. Kroszczynski AC, Kohan K, Kurowski M, Olson TR, Downie SA (2013) Intraforaminal location of thoracolumbar anterior medullary arteries. Pain Med 14:808-812. https://doi.org/10.1111/pme.12056

38. Kudo K, Terae S, Asano T, Oka M, Kaneko K, Ushikoshi S, Miyasaka K (2003) Anterior spinal artery and artery of Adamkiewicz detected by using multi-detector row CT. AJNR Am J Neuroradiol 24:13-17

39. Matsuda H, Fukuda T, Iritani O, Nakazawa T, Tanaka H, Sasaki H, Minatoya K, Ogino H (2010) Spinal cord injury is not negligible after TEVAR for lower descending aorta. Eur J Vasc Endovasc Surg 39:179-186. https://doi.org/10.1016/j.ejvs.2009.11.014

40. Matsuda H, Ogino H, Fukuda T, Iritani O, Sato S, Iba Y, Tanaka H, Sasaki H, Minatoya K, Kobayashi J, Yagihara T (2010) Multidisciplinary approach to prevent spinal cord ischemia after thoracic endovascular aneurysm repair for distal descending aorta. Ann Thorac Surg 90:561-565. https://doi.org/10.1016/j.athoracsur. 2010.04.067

41. Melissano G, Bertoglio L, Civelli V, Moraes Amato AC, Coppi G, Civilini E, Calori G, de Cobelli F, del Maschio A, Chiesa R (2009) Demonstration of the Adamkiewicz artery by multidetector computed tomography angiography analysed with the open-source software OsiriX. Eur J Vasc Endovasc Surg 37:395-400. https://doi. org/10.1016/j.ejvs.2008.12.022

42. Mordasini P, El-Koussy M, Schmidli J et al (2012) Preoperative mapping of arterial spinal supply using 3.0-T MR angiography with an intravasal contrast medium and high-spatial-resolution steadystate. Eur J Radiol 81:979-984. https://doi.org/10.1016/J.EJRAD. 2011.02.025

43. Morishita K, Murakami G, Fujisawa Y, Kawaharada N, Fukada J, Saito T, Abe T (2003) Anatomical study of blood supply to the spinal cord. Ann Thorac Surg 76:1967-1971

44. Murthy NS, Maus TP, Behrns CL (2010) Intraforaminal location of the great anterior radiculomedullary artery (artery of Adamkiewicz): a retrospective review. Pain Med 11:1756-1764. https://doi.org/10.1111/j.1526-4637.2010.00948.x

45. Nakayama Y, Awai K, Yanaga Y, Nakaura T, Funama Y, Hirai T, Yamashita Y (2008) Optimal contrast medium injection protocols for the depiction of the Adamkiewicz artery using 64-detector CT angiography. Clin Radiol 63:880-887. https://doi.org/10.1016/j. crad.2008.01.009

46. Nijenhuis RJ, Jacobs MJ, Schurink GW, Kessels AGH, van Engelshoven JMA, Backes WH (2007) Magnetic resonance angiography and neuromonitoring to assess spinal cord blood supply in thoracic and thoracoabdominal aortic aneurysm surgery. J Vasc Surg 45:71-77; discussion 77-8. https://doi.org/10.1016/j.jvs. 2006.08.085

47. Nijenhuis RJ, Jacobs MJ, Jaspers K, Reijnders M, van Engelshoven JMA, Leiner T, Backes WH (2007) Comparison of magnetic resonance with computed tomography angiography for preoperative localization of the Adamkiewicz artery in thoracoabdominal aortic aneurysm patients. J Vasc Surg 45:677-685. https://doi.org/10. 1016/j.jvs.2006.11.046

48. Nishida J, Kitagawa K, Nagata M, Yamazaki A, Nagasawa N, Sakuma H (2014) Model-based iterative reconstruction for multidetector row CT assessment of the Adamkiewicz artery. Radiology 270:282-291. https://doi.org/10.1148/radiol.13122019

49. Nishii T, Kono AK, Negi N, Hashimura H, Uotani K, Okita Y, Sugimura K (2013) The feasibility of a 64-slice MDCT for detection of the Adamkiewicz artery: comparison of the detection rate of intravenous injection CT angiography using a 64-slice MDCT versus intra-arterial and intravenous injection CT angiography using a 16-slice MDCT. Int J Cardiovasc Imaging 29(Suppl 2):127-133. https://doi.org/10.1007/s10554-013-0301-z 
50. Nojiri J, Matsumoto K, Kato A, Miho T, Furukawa K, Ohtsubo S, Itoh T, Kudo S (2007) The Adamkiewicz artery: demonstration by intra-arterial computed tomographic angiography. Eur J Cardiothorac Surg 31:249-255. https://doi.org/10.1016/j.ejcts. 2006.11.024

51. Ou P, Schmit P, Layouss W, Sidi D, Bonnet D, Brunelle F (2007) $\mathrm{CT}$ angiography of the artery of Adamkiewicz with 64-section technology: first experience in children. AJNR Am J Neuroradiol 28: 216-219

52. Polaczek M, Maslanka M, Skadorwa T, Ciszek B (2014) How does Adamkiewicz artery influence blood supply to the fetal spinal cord? Ital J Anat Embryol 119:255-262

53. Rodriguez-Baeza A, Muset-Lara A, Rodriguez-Pazos M, Domenech-Mateu JM (1991) The arterial supply of the human spinal cord: a new approach to the arteria radicularis magna of Adamkiewicz. Acta Neurochir 109:57-62

54. Schurink GWH, Nijenhuis RJ, Backes WH, Mess W, de Haan MW, Mochtar B, Jacobs MJ (2007) Assessment of spinal cord circulation and function in endovascular treatment of thoracic aortic aneurysms. Ann Thorac Surg 83:S877-S881. https://doi.org/10.1016/j. athoracsur.2006.11.028

55. Takase K, Sawamura Y, Igarashi K, Chiba Y, Haga K, Saito H, Takahashi S (2002) Demonstration of the artery of Adamkiewicz at multi- detector row helical CT. Radiology 223:39-45. https://doi. org/10.1148/radiol.2231010513

56. Takase K, Akasaka J, Sawamura Y (2007) Preoperative MDCT evaluation of the artery of Adamkiewicz and its origin. J Vasc Surg 45:1086. https://doi.org/10.1016/j.jvs.2007.03.005

57. Tanaka H, Ogino H, Minatoya K, Matsui Y, Higami T, Okabayashi H, Saiki Y, Aomi S, Shiiya N, Sawa Y, Okita Y, Sueda T, Akashi H, Kuniyoshi Y, Katsumata T (2016) The impact of preoperative identification of the Adamkiewicz artery on descending and thoracoabdominal aortic repair. J Thorac Cardiovasc Surg 151: 122-128. https://doi.org/10.1016/j.jtcvs.2015.07.079

58. Uotani K, Yamada N, Kono AK, Taniguchi T, Sugimoto K, Fujii M, Kitagawa A, Okita Y, Naito H, Sugimura K (2008) Preoperative visualization of the artery of Adamkiewicz by intra-arterial CT angiography. AJNR Am J Neuroradiol 29:314-318. https://doi.org/ 10.3174/ajnr.A0812

59. Williams GM, Perler BA, Burdick JF, Osterman FA Jr, Mitchell S, Merine D, Drenger B, Parker SD, Beattie C, Reitz BA (1991) Angiographic localization of spinal cord blood supply and its relationship to postoperative paraplegia. J Vasc Surg 13:23-33 discussion 33-5

60. Yingbin J, Jiefei M, Jian L, Yonghui S, Haiyan P, Baimeng Z, Weigoo F (2013) Evaluation of the thoracic aortic dissection treated by endografts covering a longer distance of aorta according to the location of the Adamkiewicz artery. Thorac Cardiovasc Surg 61: 569-574. https://doi.org/10.1055/s-0032-1322629

61. Yoshioka K, Niinuma H, Ehara S, Nakajima T, Nakamura M, Kawazoe K (2006) MR angiography and CT angiography of the artery of Adamkiewicz: state of the art. Radiographics 26(Suppl 1): S63-S73. https://doi.org/10.1148/rg.26si065506

62. Zhao S, Logan L, Schraedley P, Rubin GD (2009) Assessment of the anterior spinal artery and the artery of Adamkiewicz using multi-detector CT angiography. Chin Med J 122:145-149

63. Griepp RB, Ergin MA, Galla JD, Lansman S, Khan N, Quintana C, McCollough J, Bodian C (1996) Looking for the artery of Adamkiewicz: a quest to minimize paraplegia after operations for aneurysms of the descending thoracic and thoracoabdominal aorta. J Thorac Cardiovasc Surg 112:1202-1213 discussion 1213-5

64. Buffolo E, da Fonseca JHP, de Souza JAM, Alves CMR (2002) Revolutionary treatment of aneurysms and dissections of descending aorta: the endovascular approach. Ann Thorac Surg 74:S1815S1817 discussion S1825-32

65. Ishimaru S, Kawaguchi S, Koizumi N, Obitsu Y, Ishikawa M (1998) Preliminary report on prediction of spinal cord ischemia in endovascular stent graft repair of thoracic aortic aneurysm by retrievable stent graft. J Thorac Cardiovasc Surg 115:811-818. https://doi.org/10.1016/S0022-5223(98)70360-5

66. Safi HJ, Miller CC, Carr C, Iliopoulos DC, Dorsay DA, Baldwin JC (1998) Importance of intercostal artery reattachment during thoracoabdominal aortic aneurysm repair. J Vasc Surg 27:58-66 discussion $66-8$

67. Wadouh F, Wadouh R, Hartmann M, Crisp-Lindgren N (1990) Prevention of paraplegia during aortic operations. Ann Thorac Surg 50:543-552

68. Taira Y, Marsala M (1996) Effect of proximal arterial perfusion pressure on function, spinal cord blood flow, and histopathologic changes after increasing intervals of aortic occlusion in the rat. Stroke 27:1850-1858

69. Yoshioka K, Niinuma H, Kawazoe K, Ehara S (2005) Threedimensional demonstration of the collateral circulation to the artery of Adamkiewicz via internal thoracic artery with 16-row multi-slice CT. Eur J Cardiothorac Surg 28:492. https://doi.org/10.1016/j.ejcts. 2005.04.043

Publisher's note Springer Nature remains neutral with regard to jurisdictional claims in published maps and institutional affiliations. 